Научная статья

УДК 551.521.5:577.4.621.03

DOI 10.18101/2587-7143-2021-4-54-62

\title{
ВЗАИМОЗАВИСИМОСТЬ КАК ОСНОВА ЖИЗНИ НООСФЕРЫ: ФАКТЫ, ПРОЕКТЫ, РЕШЕНИЯ (ОБУЧАЮЩИЙ ТРЕНИНГ-КУРС)
}

\section{(C) Григорьева Марина Александровна}

кандидат географических наук, доцент,

Бурятский государственный университет имени Доржи Банзарова

Россия, 670000, г. Улан-Удэ, ул. Смолина, 24а

marina.grigoryeva2015@bk.ru

\section{(C) Маркелов Данила Андреевич}

доктор технических наук, член-корреспондент РАЕН, научный сотрудник, Ассоциация КАРТЭК

Россия, 117292, Москва, а/я 145

markelov@geoecostd.com

\section{(C) Алешко-Ожевская Ольга Сергеевна}

научный сотрудник,

Ассоциация КАРТЭК

Россия, 117292, Москва, а/я 145

pink@dmpink.ru

\section{(C) Акользин Андрей Павлович}

доктор технических наук, профессор, генеральный директор,

Ассоциация КАРТЭК

Россия, 117292, Москва, а/я 145

cartec@cnt.ru

\section{(C) Минеева Надежда Яковлевна}

доктор географических наук, профессор, профессор КНР, академик РАЕН, лауреат премии правительства РФ в области науки и техники, научный сотрудник, Ассоциация КАРТЭК

Россия, 117292, Москва, а/я 145

mineeva@geoecostd.com

Аннотация. В настоящей работе представлен обзор авторских исследований в области геоэкологии и географии природопользования. Взаимозависимость определяет существование ноосферы как функционирующих сообществ, как единых взаимосвязанных систем. Научно-методические разработки верифицированы на разных природных и природно-технических территориях, реализованы в виде технологий и проектов. Созданы аппаратно-программные модули ГИС, включающие алгоритмы распознавания, базы данных. Основу для каждой территории составляет проект «Геоэкологический стандарт» с диапазонами функционирования, нормативами вмешательства и обучающим тренинг-курсом. Исследования проведены впервые и не имеют аналогов в мире. Создан национальный банк нормативов щадящего природопользования.

Ключевые слова: биобарьеры, биосфера, гештальтгеография, геохимические ландшафты, геосистема, ландшафт, природопользование, экосистема. 
М. А. Григорьева, Д. А. Маркелов, О. С. Алешко-Ожевская, А. П. Акользин, Н. Я. Минеева. Взаимозависимость как основа жизни ноосферы: факты, проекты, решения

\section{Для цитирования}

Взаимозависимость как основа жизни ноосферы: факты, проекты, решения (обучающий тренинг-курс) / М. А. Григорьева, Д. А. Маркелов, О. С. Алешко-Ожевская [и др.] // Вестник Бурятского государственного университета. Биология, география. 2021. № 4. C. 54-62.

\section{Факты}

Территория - стратегический ресурс государства [13], а геополитика географический разум государства [28].

Законы и правила $[11 ; 12]$ : вся жизнь в биосфере развивается по единым законам во взаимосвязи, все закономерности, характерные для живого, имеют адаптивный характер, каждый организм, вид, популяция, сообщество выступают индикатором окружающей среды.

Территория государства представляет объединение соседних ландшафтов в единую парагенетическую систему за счет одного или нескольких доминирующих физико-географических процессов, осуществляющих основной энергообмен и обусловливающих вещественно-энергетическую целостность этой системы. К парагенетическим относятся ландшафты геохимические. Территориальная привязанность обусловливает и определяет развитие жизни: это адаптация обитателей, формирование региональных этнических диет, щадящее природопользование.

Советское пространство. Основа: советское пространство как территория приятия решений $[14 ; 22]$

Советское пространство - это универсальная конструкция, определяющая экологическую устойчивость территории. Особенности советского пространства должны быть учтены и при экологическом зонировании территории и создании сети особо охраняемых природных территорий, при разработке экологического (природно-экологического) каркаса и/или эконета». Советское пространство для природопользования - территория СССР как совокупность ландшафтов, отображена на рисунке 1 - Геохимические ландшафты.

\section{Основа: геохимический ландшафт как адаптационный синдром}

Функционирование систем живого служит основным регулятором общеземных процессов (Вернадский). Геохимический ландшафт - это метка адаптационного синдрома живых организмов, биоценозов и экосистем. Гештальтгеография - это руководящий инструмент природопользования. На примере геохимических ландшафтов показаны ореолы сходных признаков разных территорий, формирующих адаптационный синдром.

\section{Инфраструктура}

1. Инфраструктурные (трансграничные, интразональные) объекты на территории выполняют жизнеобеспечивающие функции геосистем: земля, недра, воздух, реки, водоёмы, подземные воды, биота.

2. Инфраструктура жизнеобеспечения страны, государства - это промышленность, сельское хозяйство, энергетика, транспорт, связь, образование, здравоохранение, наука, культура.

3. Инфраструктура, как кровеносная система единого организма, не может подлежать приватизации, не может быть в частной собственности.

4. Потому что не может быть никогда.

5. Никто не может приватизировать трансграничный перенос. 
6. Приватизация инфраструктуры - это элиминирующий фактор, ведущий к разрушению и гибели цивилизации.

«В чем главный, стратегический ресурс России? Не в газе, не в нефти самих по себе. А в 1/9 земной суши, удельная капитализация совокупных ресурсов которой в пять раз ниже, чем в среднем по земному шару!» [29]

«Россия сегодня - главный земной заповедник некапитализированных ресурсов, глобальная неподнятая целина, вторая Антарктида, где лежит под спудом свыше $12 \%$ мировых ресурсов всех типов (в том числе остаточный ресурс склонности тающего населения к науке и новаторству).

Один лишь экстенсивный подъем уровня их капитализации до среднемирового уже способен дать прирост всемирного валового продукта в полтора раза!

Человечество просто вынуждено взяться за эту задачу — с нашим ли участием либо без нас.

Здесь - главная угроза суверенитету, целостности страны.

И здесь же - главный ресурс возрождения, материальная основа стратегии вхождения в будущее.

Организовать и возглавить глобальный процесс освоения российских ресурсов.

Дать возможность всем конструктивным и добросовестным участникам заработать долю - не в основном капитале материального тела страны, а в приросте ее стоимости.

И при этом не только сохранить нашу собственность на национальные богатства, но и кратно приумножить их».

Основа: ландшафт как сеть инфраструктурных соединяющих объектов, включая границы, железнодорожные и автомобильные магистрали, линии электропередач, трубопроводы, поселения

Географические границы - типичные биобарьеры с функциями разделения и связи, представляют собой сгущение жизни и механизм защиты биосферы: здесь формируются новые сообщества, более устойчивые к воздействию, возникает адаптационный синдром. Территория как ресурс государства и объединяющая инфраструктура составляют предмет базового дохода или природной ренты.

Сила Кориолиса - западный перенос:

«Сохранение нетронутой природы рассматривается многими как основной фактор глобальной экологической безопасности. В силу этого российская территория выступает районом компенсации глобальных загрязнений и вообще нарушений природы. Мир активно «осваивает» экологический ресурс России, БЕСПЛАТНО - замечу — ИСПОЛЬЗУЕТ» [15, с. 123].

В подтверждение концепции приведем некоторые цитаты профессора Н. Н. Клюева [15]: «Исследование показало: несмотря на относительную природно-географическую изолированность от других стран, Россия формирует весьма тесные и обширные экологические взаимоотношения со своими соседями. Площадь водосборных бассейнов, где формируется «импортируемый» Россией речной сток, и площадь российской территории соотносятся как 1:8. Зона российских гидроэкологических интересов за рубежом охватывает бассейн Северского Донца, весь северный Казахстан восточнее $60^{\circ}$ с.ш., почти треть площади Монголии, обширные территории северо-восточного Китая, бассейн Немана, окаймляющий Калининградский эксклав. Вследствие западного переноса 
М. А. Григорьева, Д. А. Маркелов, О. С. Алешко-Ожевская, А. П. Акользин, Н. Я. Минеева. Взаимозависимость как основа жизни ноосферы: факты, проекты, решения

воздушных масс зона атмосферно-экологических «интересов» России простирается вплоть до Пиренейского полуострова. До 60\% выпадений антропогенных серы и азота на европейской территории России происходит из Западной и Центральной Европы, но и в азиатской части эта величина составляет около 10\%. Главными экспортерами воздушных загрязнений посредством дальнего переноса выбросов выступают Украина, Польша, Германия. Главными районами концентрации внешних экологических угроз безопасности России выступают китайское Приамурье, китайско-казахстанское Прииртышье, украинская часть бассейна Северского Донца. Высокая политико-экологическая напряженность в бассейне трансграничного Амура определяется большой разностью потенциалов в нагрузке на природную среду между Россией и Китаем, асинхронностью трансграничного природопользования (его интенсификацией в Китае и хозяйственным опустыниванием на пограничной периферии Забайкалья и юга Дальнего Востока), а также институциональной нерешенностью водно-экологической проблемы в бассейне из-за жесткой позиции КНР» $[15$, c. 44]: «Анализ внешних угроз экологической безопасности страны закладывает основы новой перспективной ветви географической науки - эколого-политической географии, нацеленной на познание новых экологических факторов, определяющих международную политику» [15, с. 45].

Таким образом, показана значимая биосферная функция территории России для Евразии - очищающая и оздоровительная. Эта функция выполняется безвозмездно, только на основе разумного природопользования государством, которое регулирует и сохраняет устойчивое развитие биомов на территории. Оценка биосферных функций проанализирована на примере урочища «Копнинский лес» в Сергиево-Посадском административном районе Московской области $[21 ; 25 ; 26]$.

\section{Решения и реализация}

Главная задача управления природопользованием - непревышение потенциала вместимости экосистем, который может быть установлен только в результате исследований и разработки геоэкологического стандарта территории.

Модули ГИС «Геоэкологический стандарт территории». Модули представляют приборы контроля и обеспечения безопасности территории, содержат обучающие программы, деловые игры, тренинг-курсы (рис. 1-2).

Результаты исследований реализованы в виде технологий, использованных при реализации проектов и программных модулей геоэкологического стандарта территорий.

Разработан и внедрен учебный курс: Григорьева М. А., Маркелов Д. А., Полынова О. Е. Оценка экологического состояния территории: эталоны природы типовое состояние экосистем Иволгинской котловины: учебное пособие. УланУдэ: Изд-во Бурят. гос. ун-та, 2011. 168 с. (рис. 2).

1. Стандарт образования: в системе современных стандартов высшего профессионального образования экологическое направление составляет базовую часть циклов дисциплин: гуманитарных, социальных и экономических, математических и естественно-научных, профессиональных, и формирует базовый информационный каркас последующих дисциплин направления «Экология и природопользование» и «География». Рекомендовано Учебно-методическим советом БГУ в качестве учебного пособия для студентов очной и заочной форм обучения направлений 022000 Экология и природопользование, 021000 География. 

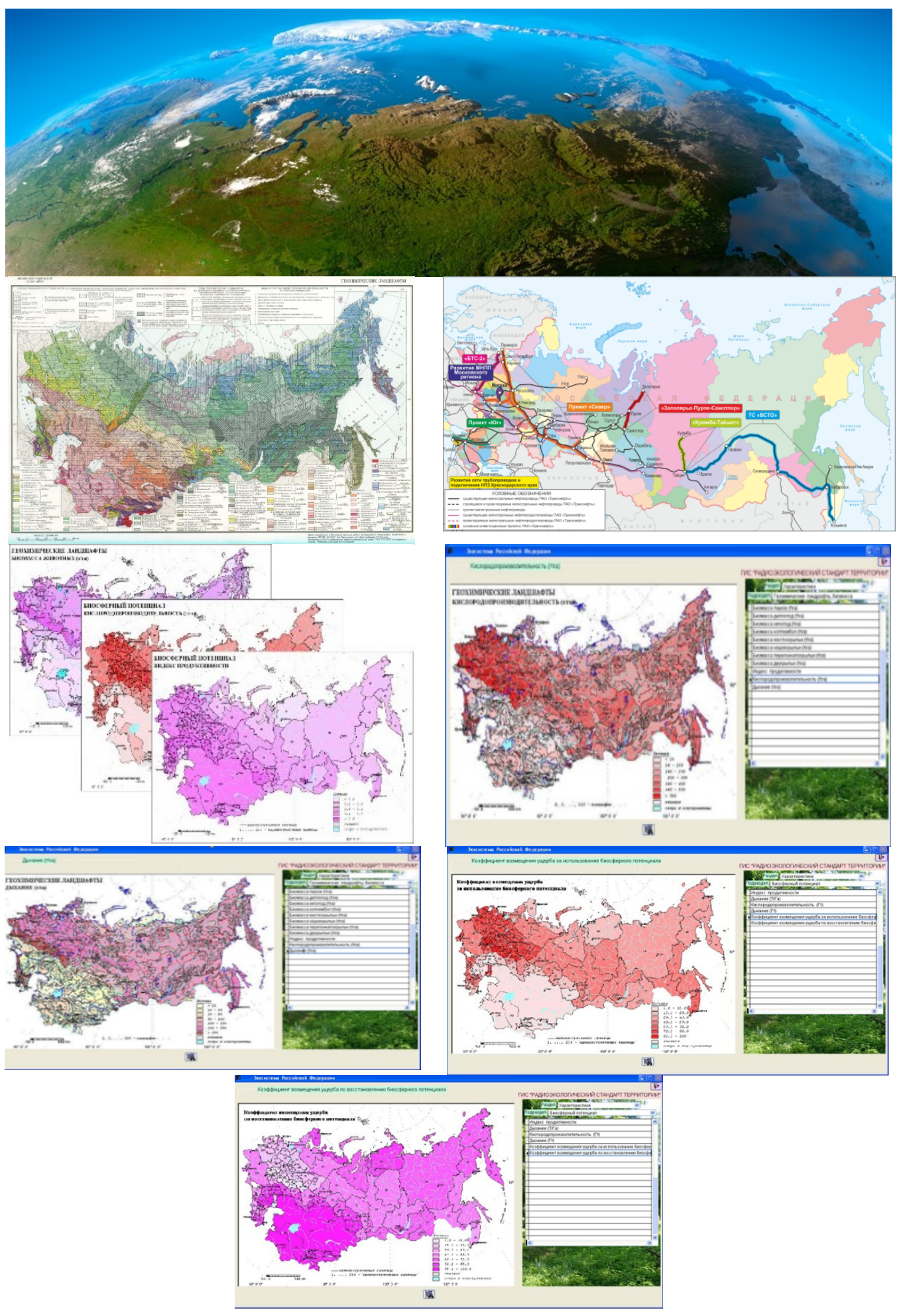

Рис. 1. Территория - стратегический ресурс государства советское пространство России и сопредельных государств 
М. А. Григорьева, Д. А. Маркелов, О. С. Алешко-Ожевская, А. П. Акользин, Н. Я. Минеева. Взаимозависимость как основа жизни ноосферы: факты, проекты, решения

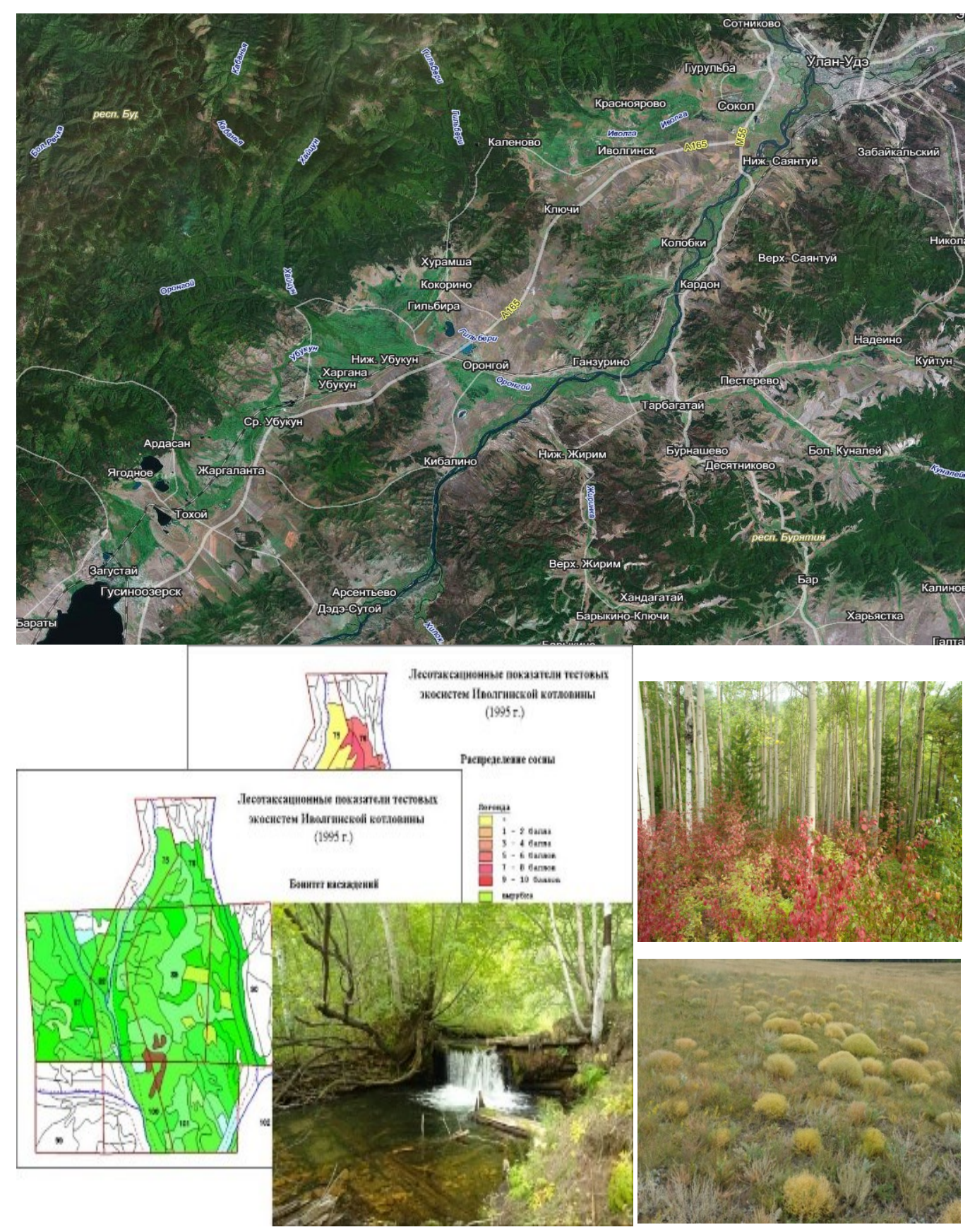

Рис. 2. Территория - стратегический ресурс государства проект «Иволгинская котловина — ворота в Азию»

2. Стандарт методический. Создание геостандарта территории требует квалифицированных кадров, для практической подготовки которых целесообразно использовать территории, для которых разработаны геостандарты. Одной из таких территорий является Иволгинская котловина, типичная для Забайкалья (Бу- 
рятия). Учебное пособие содержит методические рекомендации для описания экологического состояния территорий как эталонов в системе мониторинга.

Территориальные эталоны составляют геоэкологический стандарт территории, на основе которого должно быть управление природопользованием. Геостандарт определяет экологическую емкость и биосферный потенциал территории. На примере экосистем Иволгинской котловины показано применение оценки экологического состояния как метода мониторинга.

3. Стандарт - эталон природы (ГИС). Учебное пособие представляет информацию базы данных созданных конкретных модулей ГИС стандартов территории, отражающих типичное ландшафтно-зональное геоэкологическое состояние с оценкой индекса радиационной опасности.

4. Стандарт научный - международный. Сертификат участника международной выставки-презентации учебно-методических изданий // Золотой фонд отечественной науки. Российская академия естествознания. Москва, 2014.

5. Стандарт научный - всероссийский. Лучшее учебно-методическое издание в отрасли // Диплом лауреата всероссийской выставки // Золотой фонд отечественной науки. Российская академия естествознания. Москва, 2014.

Определены перспективы практического использования разработанных стандартов в природопользовании при создании инвестиционных паспортов тестовых территорий. Создана модель практических действий по улучшению природопользования тестовых территорий. Представлены научно-практические рекомендации для организации мониторинга.

Практические действия [11]

Теперь мы знаем формулу и следствия - «постигая взаимозависимость, мы устраняем неведение»

Первое следствие: знание.

1. География - мать всех наук! География объединяет! «Таким образом, обучение географии имеет троякую задачу: она должна будить в детях вкус к естественным наукам в целом, она должна привести их к мысли, что все люди независимо от их национальности - братья, и, наконец, она должна приучить их уважать «низшие расы» [2].

2. Парагенетические геосистемы взаимодействуют и объединяют.

3. Инвестор всегда действует на территории: преобразовывает парагенетические геосистемы или дает толчок для преобразования.

Второе следствие: ответственность.

1. Территория - стратегический ресурс государства.

2. Природную ренту — каждому.

Третье следствие: управление.

Вменить инвестору в инвестиционный паспорт пункты:

1) утилизация отходов,

2) экопросвещение на базе проекта с организацией экологической тропы, учебных тренинг-курсов для оценки ущерба и пользы проекта,

3) восстановление биопотенциала территории (измененного вследствие воздействия проекта) в соответствии с геоэкостандартом территории. 
М. А. Григорьева, Д. А. Маркелов, О. С. Алешко-Ожевская, А. П. Акользин, Н. Я. Минеева. Взаимозависимость как основа жизни ноосферы: факты, проекты, решения

\section{Литература}

1. Методология геоэкологической стандартизации территории как основа сохранения и контроля жизнеобеспечивающих ресурсов геосферных оболочек / М. А. Григорьева, Д. А. Маркелов, А. В. Маркелов [и др.] // Монгол орны газарзүйн асуудал. 2014. № 1(10). H. 173-180. Journal of Geographical Review of Mongolia. Текст: непосредственный.

2. Геоэкологический стандарт территории как базис инвестиционных проектов природопользования (обучающий тренинг-курс) / М. А. Григорьева, Д. А. Маркелов, О. Л. Алешко-Ожевская [и др.] // Трансграничные территории востока России: факторы, возможности и барьеры развития: материалы международной научно-практической конференции (Улан-Удэ, 6-8 сентября 2021 г.). Улан-Удэ, 2021. С. 209-216. Текст: непосредственный.

3. Парагенетические геосистемы: методы познания, функции, задачи, сценарии практических действий (обучающий тренинг-курс) / М. А. Григорьева, Д. А. Маркелов, О. Л. Алешко-Ожевская [и др.] // Трансграничные территории востока России: факторы, возможности и барьеры развития: материалы международной научно-практической конференции (Улан-Удэ, 6-8 сентября 2021 г.). Улан-Удэ, 2021. С. 217-224. Текст: непосредственный.

4. Каганский В. Л. Советское пространство: ландшафтный и экологический аспект // Лабиринт. 2012. № 5. С. 26-36. Текст: непосредственный.

5. Клюев Н. Н. Экологическая безопасность России и ее регионов: внешние и внутренние угрозы // Проблемы регионального развития. Модели и эксперименты: сборник статей / под редакцией Ю. Г. Липеца, С. Б. Шлихтера. Москва: ИГ РАН, 1997. С. 121126. Текст: непосредственный.

6. Природная рента - право на жизнь / Д. А. Маркелов, А. В. Маркелов, Н. Я. Минеева [и др.] // Московский экономический журнал. 2018. № 5. URL: http://je.su/rekreacia-iturizm/moskovskij-ekonomicheskij-zhurnal-5-2018-18 (дата обращения: 08.11.2020). Текст: электронный.

7. Технологии географической индустрии / Д. А. Маркелов, А. В. Маркелов, Н. Я. Минеева [и др.] // Московский экономический журнал. 2018. № 5. URL: //http:/qje.su/nauki-o-zemle/moskovskij-ekonomicheskij-zhurnal-5-2018-16/ (дата обращения: 08.11.2020). Текст: электронный.

8. Геоэкостандарт: концепция, биосферная функция, факты и практические решения / Д. А. Маркелов, Н. Я. Минеева, А. П. Акользин [и др.] // Московский экономический журнал. 2019. URL: https:/qje.su/rekreacia-i-turizm/moskovskij-ekonomicheskijzhurnal-12-2019-6/ (дата обращения: 08.11.2020). Текст: электронный.

9. Геоэкологический стандарт территории как базис инвестиционных проектов природопользования или предотвращенный экологический ущерб - цена жизни (обучающий тренинг-курс). / Д. А. Маркелов, Н. Я. Минеева, А. П. Акользин [и др.] // International agricultural Journal. 2020. Vol 63, No 6. P. 233-243. URL: https://iacj.eu/index.php/iacj/article/view/298//https://iacj.eu/index.php/iacj/article/view/298/30 7 (дата обращения: 08.11.2020). Текст: электронный.

10. Хаусхофер К. О геополитике. Работы разных лет. Москва: Мысль, 2001. 426 с. Текст: непосредственный.

11. Чернышёв С. О том, чего не оказалось в «Стратегии-2020» // Человечество вынуждено взяться за капитализацию России - с нашим ли участием либо без нас. URL: https://dayofru.com/article/5ca79975d153f7d7560713a0 (дата обращения: 08.11.2020). Текст: электронный.

Статья поступила в редакцию 11.10.2021; одобрена после рецензирования 08.11.2021; принята к публикации 06.12.2021. 


\section{MUTUALITY AS A BASIS OF NOOSPHERE LIFE: FACTS, PROJECTS, SOLUTIONS (A TRAINING COURSE)}

Marina A. Grigoryeva

Cand. Sci. (Geogr.), A/Prof.,

Dorzhi Banzarov Buryat State University

24a Smolina St., Ulan-Ude 670000, Russia

marina.grigoryeva2015@bk.ru

Danila A. Markelov

Dr. Sci. (Engineering), Corresponding Member of the RANS, Researcher,

KARTEK Association

145 P. O. Box, Moscow 117292, Russia

markelov@geoecostd.com

Olga S. Aleshko-Ozhevskaya

Researcher

KARTEK Association

145 P. O. Box, Moscow 117292, Russia

pink@dmpink.ru

Andrey P. Akolzin

Dr. Sci. (Engineering), Prof., General Director,

General Director

KARTEK Association

145 P. O. Box, Moscow 117292, Russia

cartec@cnt.ru

Nadezhda Ya. Mineeva

Dr. Sci. (Geogr.), Prof., Prof. of the PRC

Academician of the RANS, Laureate of the RF Government Prize

in Science and Technology, Researcher,

KARTEK Association

145 P. O. Box, Moscow 117292, Russia

mineeva@geoecostd.com

Abstract. This article provides an overview of the author's research in the field of geoecology and geography of nature management. Mutuality determines the existence of the noosphere as functioning communities, single interconnected systems. We verified scientific and methodological developments in various natural and natural-technical territories, implemented them in the form of technologies and projects, created GIS hardware and software modules, including recognition algorithms, and databases. The basis for each territory was the "Geoecological Standard" project with functional ranges, intervention standards, and a training course. The studies were carried out for the first time and have no analogues in the world. We also created a national bank of environmental standards.

Keywords: biobarriers, biosphere, gestalt geography, geochemical landscapes, geosystem, landscape, nature management, ecosystem.

For citation

Grigoryeva M. A., Markelov D. A., Aleshko-Ozhevskaya O. S., Akolzin A. P., Mineeva N. Ya. Mutuality as a Basis of Noosphere Life: Facts, Projects, Solutions (A Training Course). Bulletin of Buryat State University. Biology, Geography. 2021; 4: 54-62 (In Russ.).

The article was submitted 11.10.2021; approved after reviewing 08.11.2021; accepted for publication 06.12.2021. 